\title{
PENDEKATAN SUFISTIK DALAM PEMBELAJARAN PENDIDIKAN AGAMA ISLAM
}

\author{
A. Qomarudin \\ Dosen STAI Ma'had Aly Al-Hikam Malang - Indonesia \\ Email: masqomarudinyes@gmail.com
}

\begin{abstract}
Education has the main goal to develop the all potentials of human beings, including; intellectual, emotional and spiritual. The problems that arise from the education such as fights, killings, brawls between students, and so on, certainly cannot be separated from the dry taste in the knowledge that has been obtained. So it is important in this case to discuss the spiritual side which is one part of intelligence possessed by humans through the Sufistic approach as a step in developing Islamic religious education learning. The sufistic approach in learning of Islamic education can be done through riyadlah (mental exercises) gradually with taking into the students condition. The process of riyadlah can be done by carrying out some material in Sufistic learning, which includes moral sufistic (tasawuf akhlaqi), practice sufistic (tasawuf amali), and philosophical sufistic (tasawuffalsasi).

Pendidikan memiliki tujuan utama untuk mengembangkan seluruh potensi diri manusia, yang di antaranya; intelektual, emosional, dan spiritual. Pemasalahan yang muncul dari dunia pendidikan seperti perkelahian, pembunuhan, tawuran antar pelajar, dan lain sebagainya, tentunya tidak terlepas dari keringnya cita rasa pada ilmu pengetahuan yang telah diperoleh. Sehingga penting dalam hal ini untuk membahas sisi spiritual yang menjadi salah satu bagian kecerdasan yang dimiliki oleh manusia melalui pendekatan sufistik sebagai langkah dalam melakukan pengembangan pembelajaran pendidikan agama Islam. Pendekatan sufistik dalam pembelajaran pendidikan agama Islam dapat dilakukan melalui riyadlah (latihan-latihan jiwa) secara bertahap dengan memperhatikan keadaan peserta didik. Proses riyadlah dapat dilakukan dengan cara melaksanakan beberapa materi dalam pembelajaran sufistik, yang mencakup tasawuf akhlaqi, tasawuf amali, dan tasawuf falsafi.
\end{abstract}

Kata kunci: Pendekatan Sufistik, Pembelajaran PAI 


\section{A. Pendahuluan}

Berdasarkan pada apa yang disebutkan dalam undang-undang sistem pendidikan nasional tentang pendidikan, yang mengatakan bahwa Pendidikan adalah usaha sadar dan terencana untuk mewujudkan suasana belajar dan proses pembelajaran agar peserta didik secara aktif mengembangkan potensi dirinya untuk memiliki kekuatan spiritual keagamaan, pengendalian diri, kepribadian, kecerdasan, akhlak mulia, serta keterampilan yang diperlukan dirinya, masyarakat, bangsa, dan negara. ${ }^{1}$ Maka tujuan pendidikan yang mendasar adalah mengembangkan potensi diri peserta didik, baik kognitif, afektif, maupun psikomotorik. Dengan bahasa yang lain, pada diri manusia terdapat 3 kecerdasan; intelektual, emosional, dan spiritual yang harus dikembangkan melalui langkah pendidikan.

Harapan dari pendidikan adalah munculnya orang-orang yang berilmu pengetahuan luas dan memiliki kedalaman spiritual. Dalam hal ini munculnya seorang yang pinter (pandai) yang menggunakan akalnya dan seorang yang bener (benar) yang menggunakan hatinya memang menjadi harapan besar dari terselenggarakannya suatu pendidikan. Karena apabila hanya menyandang pandai, maka kepandaian yang dimiliki akan dapat dikendalikan oleh nafsunya. Sedangkan apabila dia hanya menyandang benar, maka kebenarannya tersebut tidak dapat menembus dunia rasional yang cermat. Maka sangat diharapkan antara pandai dan benar ini dapat berjalan berdampingan untuk menuju insan kamil yang dicita-citakan dalam pendidikan.

Beberapa pemasalahan yang muncul dari dunia pendidikan seperti perkelahian, pembunuhan, tawuran antar pelajar, dan lain sebagainya, tentunya tidak terlepas dari keringnya cita rasa dari ilmu pengetahuan yang telah diperoleh. Oleh karena itu, menjadi sangat penting dalam hal ini untuk mempelajari sisi spiritual yang merupakan salah satu kecerdasan yang dimiliki oleh manusia melalui pendekatan sufistik sebagai langkah dalam melakukan pengembangan pembelajaran pendidikan agama Islam.

\section{B. Pengertian, Sumber, dan Tujuan Ajaran Sufistik}

Banyak pendapat yang mendefinisikan kata sufi, ada yang mengatakan kata tersebut berasal dari kata shafa yang berarti bersih, sehingga kata shufi memiliki makna orang yang hatinya tulus dan bersih dihadapan Tuhannya. Ada pendapat lain yang mengatakan berasal dari kata shuffah yang berarti serambi masjid Nabawi di Madinah yang ditempati oleh para sahabat Nabi yang miskin dari golongan Muhajirin,

${ }^{1}$ Undang-undang Sistem Pendidikan Nasional (Bandung: Citra Umbara, 2010), Cet II. HIm. 2. 
dan mereka itu disebut dengan ahlu as-suffah. Selain itu juga ada pendapat yang mengatakan berasal dari kata suf yang berarti kain yang dibuat dari bulu (wool) dan kaum sufi lebih memilih wool yang kasar sebagai simbol kesederhanaan. Ada juga pendapat yang mengatakan bahwa kata shufi berasal dari bahasa Yunani shopos yang berarti hikmah. ${ }^{2}$ Dari beberapa pendapat yang ada, pendapat yang mengatakan kata sufi diambil dari kata suf yang berarti wool adalah pendapat yang lebih diterima. Karena dengan berpakaian sederhana itu, mereka merasa terhindar dari sifat ria' dan lebih menunjukkan kezuhudan.

Dari banyaknya definisi tasawuf secara terminologis sesuai dengan subjektifitas masing-masing sufi, maka Ibrahim Basyuni mengklasifikasikan tasawuf menjadi 3 macam yang menunjukkan elemenelemen, ${ }^{3}$ yakni:

1. Al-bidayah sebagai pengalaman ahli sufi tahap pemula, yang mengandung arti bahwa seseorang secara fitrahnya sadar dan mengakui bahwa semua yang ada ini tidak dapat menguasai dirinya sendiri karena dibalik yang ada terdapat realitas mutlak, dan elemen ini dapat disebut sebagai tahap kesadaran tasawuf.

2. Al-mujahadah sebagai pengamalan praktis ahli sufi yang merupakan tahap perjuangan keras, karena jarak antar manusia dengan realitas mutlak yang mengatasi semua yang ada bukan jarak fisik yang berupa rintangan dan hambatan, maka dari itu diperlukan kesungguhan dan perjuangan yang keras untuk mencapai dan menempuh jarak tersebut dengan cara menciptakan kondisi tertentu untuk dapat mendekatkan diri dengan realitas mutlak.

3. Al- Madzaqat sebagai pengalaman dari segi perasaan, jadi ketika seseorang telah lulus melewati hambatan dan rintangan untuk mendekatkan diri dengan realitas mutlak, maka ia akan dapat berkomunikasi dan berada sedekat mungkin dihadirat-Nya serta akan merasakan kelezatan spiritual yang didambakan.

Karena tasawuf sudah menjadi sebuah disiplin ilmu, maka Harun nasution mendefinisikan tasawuf sebagai ilmu yang mempelajari cara dan jalan bagaimana orang Islam dapat sedekat mungkin dengan Allah agar dapat memperoleh hubungan langsung dengan-Nya, artinya bagaimana diri seseorang dapat betul-betul berada di kehadirat-Nya. ${ }^{4}$ Dengan demikian, intisari dari sufisme adalah kesadaran akan adanya komunikasi dan dialog antara ruh manusia dengan realitas mutlak (Allah) yang dapat diperoleh dengan melalui beberapa usaha tertentu.

\footnotetext{
${ }^{2}$ Supiana dan M. Karman, Materi Pendidikan Agama Islam (Bandung: Remaja Rosdakarya, 2009), Cet. IV, hlm. 218.

3 Supiana dan M. Karman, Ibid.

${ }^{4}$ Harun Nasution, Filsafat dan Mistisme dalam Islam (Jakarta: Bulan Bintang, 1973), hlm. 56.
} 
Dalam agama Islam yang menjadikan al-Quran dan al-Hadits sebagai sumber ajarannya, maka berkaitan dengan dasar ajaran tasawuf dapat diambil beberapa ayat al-Quran yang menjelaskan tentang hal tersebut, di antaranya adalah:

1. Surat al-Baqarah ayat 186

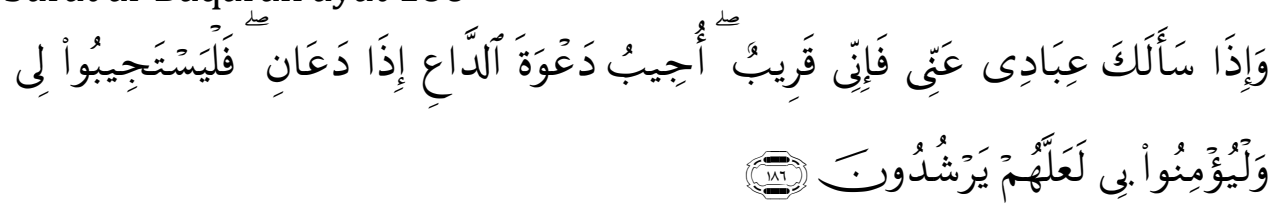

"dan apabila hamba-hamba-Ku bertanya kepadamu tentang Aku, Maka (jawablah), bahwasanya aku adalah dekat. aku mengabulkan permohonan orang yang berdoa apabila ia memohon kepada-Ku, Maka hendaklah mereka itu memenuhi (segala perintah-Ku) dan hendaklah mereka beriman kepada-Ku, agar mereka selalu berada dalam kebenaran"5

2. Surat al-Baqarah ayat 115

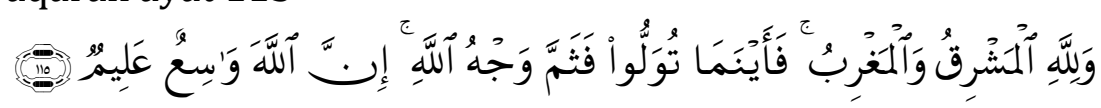

dan kepunyaan Allah-lah timur dan barat, Maka kemanapun kamu menghadap di situlah wajah Allah[83]. Sesungguhnya Allah Maha Luas (rahmat-Nya) lagi Maha mengetahui. ${ }^{6}$

[83] Disitulah wajah Allah maksudnya; kekuasaan Allah meliputi seluruh alam; sebab itu di mana saja manusia berada, Allah mengetahui perbuatannya, karena ia selalu berhadapan dengan Allah.

3. Sebuah hadits qudsi yang artinya "pada mulanya Aku adalah harta yang tersembunyi, kemudian Aku ingin kenal, maka aku ciptakan mkahluq dan mereka pun kenal pada-Ku melalui diri-Ku"7

4. Sebuah hadits Nabi yang berbunyi:

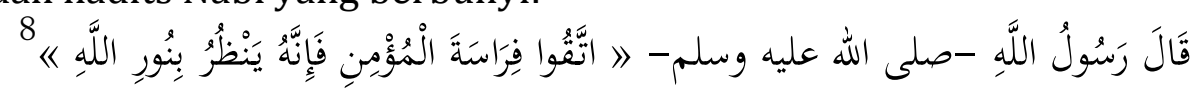

"Rasulullah saw. bersabda: takutlah kamu sekalian terhadap firasat orang mukmin, karena sesungguhnya dia memandang dengan nur (cahaya) Allah.

5. Sebuah ungkapan salafus shaleh

\footnotetext{
${ }^{5} \mathrm{Al}-\mathrm{Quran}$ in word. Ver. 1.3.

${ }^{6} \mathrm{Al}-\mathrm{Quran}$ in word. Ver. 1.3.

${ }^{7}$ Supiana dan M. Karman, hlm 224.

8 Sunan at-Tirmidzi (Maktabah Syamilah), juz. 11, hlm. 401.
} 


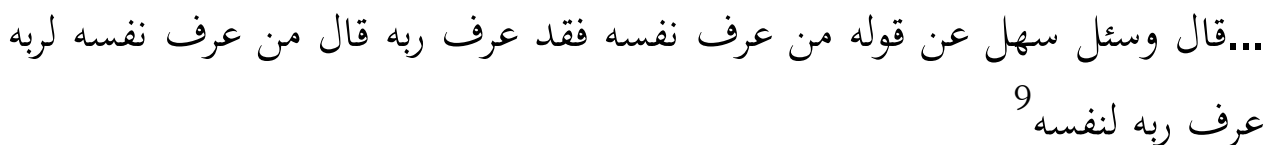

dia berkata dan Sahl ditanya tentang ucapannya "barang siapa yang mengenal dirinya maka dia mengenal Tuhannya" dia menjawab "barang siapa yang memahami dirinya bagi Tuhannya maka dia memahami Tuhannya bagi dirinya".

Terkait dengan tujuan dari tasawuf adalah sebagai bentuk pengabdian seseorang terhadap Tuhannya dalam melaksanakan salah satu tugasnya yaitu sebagai seorang 'Abd (hamba), disamping ia juga sebagai seorang khalifah (pemimpin). Karena seperti yang disampaikan oleh Muhammad Abdul Haq Ansari bahwa tidak ada tingkatan yang lebih tinggi dibanding tingkatan kehambaan ('abdiyyat) dan tidak ada kebenaran yang lebih tinggi diluar Syariah. ${ }^{10}$ Dengan demikian, untuk mencapai tujuan tasawuf seseorang harus melaksanakan berbagai kegiatan (al-mujahadah dan ar-riyadhoh), dan tidak dibenarkan apabila seseorang mengatakan tasawuf dengan memisahkan amaliyah kerohanian dengan syari'at agama Islam. ${ }^{11}$

\section{Isi Pokok Ajaran Tasawuf (Sufistik)}

Dalam hal ini ada tiga pokok ajaran tasawuf yang dapat dikembangkan dalam dunia pendidikan, antara lain adalah:

1. Tasawuf Akhlaqi

Dalam pandangan kaum sufi, manusia cenderung mengikuti hawa nafsunya, daripada manusia mengendalikan hawa nafsunya. Keinginan untuk menguasai dunia atau berusaha agar berkuasa di dunia sangatlah besar. Cara hidup seperti ini menurut Al-Ghazali, akan membawa manusia kejurang kehancuran moral. Dalam hal ini rehabilitas kondisi mental yang tidak baik adalah bila terapinya hanya didasar pada aspek lahiriyah saja. Itu sebabnya pada tahap awal kehidupan tasawuf diharuskan melakukan amalan-amalan atau latihan-latihan rohani yang cukup, tujuanya tidak lain adalah untuk membersihkan jiwa dari nafsu yang tidak baik untuk menuju kehadirat Illahi. ${ }^{12}$

\footnotetext{
${ }^{9}$ Hilyah al-Auliya' (Maktabah Syamilah), juz. 10, hlm. 208

10 Muhammad Abdul Haq Ansari, Antara Sufisme Dan Syari'ah (Jakarta: CV. Rajawali, 1990), hal. 207.

11 Amin Syukur dan Masharudin, Intelektualisme Tasawuf (Semarang: LEMBKOTA bekerjasama dengan Jakarta: Pustaka Pelajar, 2002), cet. I, hlm. 15.

${ }^{12}$ Asmaran, Pengantar Studi Tasawuf (Jakarta: PT. Raja Grafindo Persada, 2002), hlm. 67.
} 
Adapun bentuk dari usaha atau latihan-latihan jiwa (riyadloh) yang dilakukan ahli tasawuf dalam menuju kehadirat Illahi dilakukan dengan melalui tiga level (tingkatan) yakni: takhalli, tahalli, dan Tajalli.

a. Takhalli, berarti membersihkan diri dari sifat- sifat tercela, dari maksiat lahir dan maksiat batin. Di antara sifat- sifat tercela yang mengotori jiwa (hati) manusia adalah hasad (dengki), hiqd (rasa mendongkol), su'u al-zann (buruk sangka), takkabur (sombong), 'ujub (membanggakan diri), riya' (pamer), bukhl (kikir), dan ghadab (pemarah). Takhalli juga berarti mengosongkan diri dari sikap ketergantungan terhadap kelezatan hidup duniawi. Hal ini akan dapat dicapai dengan jalan menjauhkan diri dari kemaksiatan dalam segala bentuknya dan berusaha melenyapkan dorongan hawa nafsu jahat. ${ }^{13}$

b. Tahalli, yakni mensucikan diri dengan sifat-sifat terpuji, dengan ta'at lahir dan taat batin. Tahalli berarti menghiasi diri dengan jalan membiasakan diri dengan sifat dan sikap serta perbuatan yang baik. Berusaha agar dalam setiap gerak perilaku selalu berjalan di atas ketentuan-Nya. Yang dimaksud dengan ketaaatan lahir (luar) dalam hal ini adalah kewajiban yang bersifat formal seperti salat, puasa, zakat, haji dan sebagainya. Sedangkan yang dimaksud dengan ketaatan batin (dalam) adalah seperti iman, sabar, tawadlu', wara', ikhlas dan lain sebagainya. ${ }^{14}$

c. Tajalli, berarti terungkapnya nur ghaib (cahaya gaib) untuk hati. Tajalli ialah lenyap atau hilangnya hijab dari sifat-sifat kebasyariahan (kemanusiaan). Usaha ini dimaksudkan untuk pemantapan dan pendalaman materi yang telah dilalui pada fase tahalli, maka rangkaian pendidikan mental itu disempurnakan pada fase tajalli. ${ }^{15}$

Sedangkan langkah untuk melestarikan dan memperdalam rasa ketuhanan, ada beberapa cara yang diajarkan kaum sufi, antara lain adalah:

a. Munajat, artinya melaporkan diri kehadirat Allah atas segala aktifitas yang dilakukan.

b. Muraqabah dan Muhasabah, muraqabah adalah senantiasa memandang dengan hati kepada Allah dan selalu memperhatikan apa yang diciptakan-Nya dan tentang hukumhukum-Nya. Sedangkan muhasabah adalah selalu memikirkan dan memperhatikan apa yang telah diperbuat dan yang akan

${ }^{13}$ Asmaran, hlm. 68.

${ }^{14}$ Asmaran, hlm. 71.

${ }^{15}$ Asmaran, hlm. 73. 
diperbuat; dan ini muncul dari iman terhadap hari perhitungan (hari kiamat).

c. Memperbanyak wirid dan dzikir.

d. Mengingat mati.

e. Tafakkur, adalah berfikir, memikirkan, merenungkan atau meditasi atas ayat-ayat al-Quran dan fenomena alam. ${ }^{16}$

2. Tasawuf Amali

Pada dasarnya tasawuf amali adalah kelanjutan dari tasawuf akhlaki, karena seseorang tidak dapat hidup disisi-Nya dengan hanya mengandalkan amalan yang dikerjakan sebelum ia membersihkan dirinya. Jiwa yang bersih merupakan syarat utama untuk bisa kembali kepada Tuhan, karena Dia adalah Maha Bersih dan Maha Suci dan hanya menginginkan atau menerima orang-orang yang bersih. Dengan demikian, manusia diharapkan mampu mengisi hatinya (setelah dibersihkan dari sifat-sifat tercela) dengan cara memahami dan mengamalkan sifat-sifat terpuji melalui aspek lahir dan batin, yang mana kedua aspek tersebut dalam agama dibagi menjadi 4 (empat) bagian, yaitu:

a. Syari'at, adalah undang-undang atau garis-garis yang telah ditentukan yang termasuk di dalamnya hukum-hukum halal dan haram, yang diperintah dan yang dilarang, yang sunnah, makruh, mubah, dan lain sebagaonya. Dengan kata lain ini merupakan peraturan.

b. Thoriqot, adalah tata cara dalam melaksanakan syari'at yang telah digariskan dalam agama dan dilakukan hanya karena penghambaan diri kepada Allah. Dengan kata lain ini merupakan pelaksanaan.

c. Hakekat, adalah aspek lain dari syari'ah yang bersifat lahiriyah, yaitu aspek bathiniyah. Dapat juga diartikan sebagai rahasia yang paling dalam dalam dari segala amal atau inti syari'ah. Dengan kata lain ini merupakan keadaan yang sebenarnya atau kebenaran sejati.

d. Ma'rifat, adalah pengetahuan mengenai Tuhan melalui hati (qalb). Dengan kata lain ini merupakan pengenalan Tuhan dari dekat. ${ }^{17}$

Sedangkan untuk berada dekat pada Allah, seorang sufi harus menempuh jalan panjang yang berisi station-station yang disebut dengan maqamat. Beberapa urutan maqamat yang disebutkan oleh Harun Nasution adalah; taubat, zuhud, sabar, tawakal, dan rida'. Di atas maqamat ini ada lagi; mahabbah, ma'rifat, fana' baqa', serta

${ }^{16}$ Asmaran, hlm. 76-90.

${ }^{17}$ Asmaran, hlm. 95-104. 
ittihad. ${ }^{18}$ Selain istilah maqamat, ada juga istilah ahwal yang merupakan kondisi mental. Dalam hal ini ada beberapa tingkah yang sudah mashur, yaitu; khauf, raja', syauq, uns, dan yaqin. ${ }^{19}$

3. Tasawuf Falsafi

Adalah tasawuf yang ajaran-ajarannya memadukan antara visi mistis dengan visi rasional. Hal ini berbeda dengan tasawuf akhlaki dan amali, yang masih berada pada ruang lingkup tasawuf suni seperti tasawufnya al-Ghazali, tasawuf ini menggunakan terminologi falsafi dalam pengungkapan ajarannya. Ciri umum tasawuf falsafi adalah kesamaran-kesamaran ajarannya yang diakibatkan banyaknya ungkapan dan peristilahan khusus yang hanya bisa dipahami oleh mereka yang memahami ajaran tasawuf jenis ini. Kemudian tasawuf ini tidak dapat dipandang sebagai filsafat, karena ajaran dan metodenya didasarkan pada rasa (dzauq). Beberapa paham tipe ini antara lain adalah; fana' dan baqa', ittihad, hulul, wahdah al-wujud, dan isyraq. 20

\section{Peran Teori Sufistik dalam Pendidikan}

Tujuan dari penciptaan manusia oleh Allah swt. adalah sebagai 'abd (hamba) dan sekaligus khalifah (pemimpin) di muka bumi, yang di dalamnya terdapat berbagai persoalan hidup yang harus dihadapi. Akan tetapi berbagai permasalah kehidupan akan dapat dengan mudah diatasi apabila ada kedekatan seseorang dengan-Nya. Dalam hal ini, pengembangan kepribadian dapat dilakukan dalam proses pencapaian qalbun salim, karena Allah swt. hanya dapat dekat dengan hati yang jernih. Dalam proses pencapaian qalbun salim inilah, diperlukan pendidikan yang responsif terhadap pengembangan hati nurani. ${ }^{21}$ Maka pendekatan sufistiklah yang mampu memerankan sebagai pendidikan yang memperhatikan terhadap aspek ruhani.

Untuk dapat mengembangkan dasar-dasar pendekatan sufistik dalam pendidikan dapat dilakukan dengan cara mengejowantahkannya dalam pembelajaran berbagai aspek materi yang ada dalam pendidikan dengan tanpa melupakan psikologi yang dimiliki oleh peserta didik. Karena pada hakikatnya semua ilmu pengetahuan itu mengandung nilainilai pengabdian kepada Allah swt. sebagai dzat yang menguasai seluruh keilmuan.

\footnotetext{
18 Asmaran, hlm. 109.

${ }^{19}$ Asmaran, hlm. 140-149.

${ }^{20}$ Asmaran, hlm. 153-177.

21 Tim Dosen Fakultas Tarbiyah UIN Maliki, Pendidikan Islam dari Paradigma Klasik hingga Kontemporer (Malang: UIN-Malang Press: Malang, 2009), hlm. 26.
} 
Dalam buku "Pendidikan Islam dari Paradigma Klasik hingga Kontemporer" yang mengambil dari buku "psikologi sufi" menyebutkan bahwa perspektif para sufi mengatakan hakikat realitas adalah spiritual karena segala sesuatu berasal dari sang pencipta. Dalam hal ini, ada hubungan paralel yang dapat dijelaskan lebih spesifik antara realitas makrokosmos dan mikrokosmos, yaitu; dalam dunia makrokosmos terdapat tingkatan-tingkatan realitas (alam materi, alam nasut, alam malakut, alam jabarut, dan alam lahut). Sedangkan dalam dunia mikrokosmos (diir manusia) juga terdapat lapisan-lapisan (lapisan fisikal, nafs, qalb, ruh, kesadaran batin, dan kesadaran batin terdalam). Beberapa lapisan tersebut harus dilalui oleh jiwa manusia untuk mencapai kesempurnaan (kedekatan dengan Allah swt.).

Sedangkan dalam ilmu pengetahuan modern memandang hakikat realitas adalah material. Teori modern mengatakan bahwa dunia yang dapat dikaji adalah dunia yang secara valid hanyalah realitas objektif (alam materi/ lapis fisikal atau yang memiliki sifat kebendaan). Dalam hal ini, dapat dikatakan dengan sudut pandang yang sangat dangkal, karena pada hakikatnya bahwa realitas itu memiliki multi aspek, baik aspek indrawi maupun supra indrawi. ${ }^{22}$ Dengan demikian, perlu adanya keseimbangan antara aspek material yang sangat rasional dengan aspek spiritual yang irasional, dengan tujuan akhir maju dalam ilmu pengetahuan modern dengan tetap membawa tanggung jawab sebagai hamba Allah swt.

\section{E. Paradigma Pendidikan Sufistik dalam Pendidikan Islam}

Pada hakikatnya, tujuan pendidikan Islam adalah membina umat manusia agar dapat menjadi manusia yang sempurna (insan kamil). Hal ini dimaksudkan agar manusia dapat terhindar dari bebagai macam belenggu kehidupan manusia, dan mencapai kebahagiaan dalam kehidupan akhirat. Akan tetapi tujuan ideal tersebut masih jauh dari harapan, dengan disebabkan adanya beberapa hal yang salah satu diantaranya adalah pendidikan Islam yang masih mengedepankan pola hidup yang lebih dekat hubungannya dengan Tuhan dan mengesampingkan adanya sisi kehidupan dunia, sehingga seseorang akan menjadi makhluk yang gagap dengan teknologi. ${ }^{23}$ Gambaran seseorang dalam hal ini dapat dikatakan bahwa terlahir orang-orang yang dapat merasakan dengan hatinya, akan tetapi dia tidak cermat dalam memanfaatkan rasionya. Maka dalam hal ini sangatlah diperlukan suatu langkah pendidikan yang memperhatikan potensi rasa dan rasio.

22 Tim Dosen Fakultas Tarbiyah UIN Maliki, hlm. 26.

23 Dakir dan Sardimi, Pendidikan Islam dan ESQ (Komparasi-Integrasi Upaya Menuju Stadium Insan Kamil (Semarang: RaSAIL Media Group, 2011), hlm. 233-234. 
Selain itu, di lain sisi yang berhubungan dengan zaman modern juga terdapat ilmu pengetahuan yang kering dari cita rasa, yang dapat dilihat dari banyak terjadinya dekadensi kehidupan, emosi, dan moral. Hal ini menjadikan lenyapnya kekayaan ruhaniyah yang dapat digunakan sebagai alat untuk memperkokoh derajat mulia manusia di bumi ini. ${ }^{24}$ Maka dalam dunia pendidikan dan khususnya pendidikan Islam sangat diperlukan sebuah pemikiran ke arah integrasi antara ilmu pengetahuan dengan agama, yang dimaksudkan sebagai langkah menjadikan peserta didik seorang yang pandai dan penuh tanggung jawab terhadap Allah swt.

Dalam hal ini, muncul pandangan untuk dilakukannya rekonstruksi paradigma pendidikan ke arah sufistik-alternatif, yaitu sebagai berikut:

1. Landasan Filosofi, kehidupan manusia pada hakikatnya adalah menuju dan mendekatkan diri kepada Allah swt., dan Dia hanya dapat didekati dengan pribadi yang berhati jernih. Hati yang ternih dapat dicapai melalui riyadlah, yang pada akhirnya seseorang dapat mencapai kesempurnaan sebagai manusia.

2. Proses Pendidikan, berdasar pada landasan filosofis di atas, proses pendidikan diharapkan mampu membuka pintu kesadaran manusia untuk semakin mendekatkan diri kepada Allah swt., dan dalam proses pendidikan tidak hanya memperdulikan terhadap pengembangan pada dimensi fisik, tetapi juga memperhatikan dimensi non fisik. Sehingga ada keseimbangan antara rasa dan rasio, serta ada pemahaman konsep-konsep maqamat secara tepat. ${ }^{25}$

\section{F. Simpulan}

Ada beberapa hal yang menjadi kesimpulan penulis dari beberapa penjelasan di atas, di antaranya adalah:

1. Pendekatan sufistik dalam pembelajaran pendidikan agama Islam dapat dilakukan melalui riyadlah (latihan-latihan jiwa) secara bertahap dengan memperhatikan keadaan peserta didik, ini dilakukan sebagai langkah menuju kesempurnaan (kedekatan dengan Allah swt.).

2. Proses riyadlah dapat dilakukan dengan cara melaksanakan beberapa materi dalam pembelajaran sufistik, yang mencakup tasawuf akhlaqi, tasawuf amali, dan tasawuf falsafi.

24 Tim Dosen Fakultas Tarbiyah UIN Maliki, hlm. 28.

25 Tim Dosen Fakultas Tarbiyah UIN Maliki, hlm. 28-29. 
JURNAL PIWULANG, Vol. 2 No. 1 September 2019, 25-35

\section{DAFTAR RUJUKAN}

Al-Quran in word. Ver. 1.3.

Asmaran, Pengantar Studi Tasawuf (Jakarta: PT. Raja Grafindo Persada, 2002).

Dakir dan Sardimi, Pendidikan Islam dan ESQ (Komparasi-Integrasi Upaya

Menuju Stadium Insan Kamil (Semarang: RaSAIL Media Group, 2011).

Hilyah al-Auliya' (Maktabah Syamilah), juz. 10, hlm. 208

Muhammad Abdul Haq Ansari, Antara Sufisme Dan Syari'ah (Jakarta: CV.

Rajawali, 1990).

Nasution, Harun., Filsafat dan Mistisme dalam Islam (Jakarta: Bulan Bintang, 1973).

Sunan at-Tirmidzi (Maktabah Syamilah), juz. 11, hlm. 401.

Supiana dan M. Karman, Materi Pendidikan Agama Islam (Bandung: Remaja Rosdakarya, 2009).

Syukur, Amin. dan Masharudin, Intelektualisme Tasawuf (Semarang:

LEMBKOTA bekerjasama dengan Jakarta: Pustaka Pelajar, 2002).

Tim Dosen Fakultas Tarbiyah UIN Maliki, Pendidikan Islam dari Paradigma

Klasik hingga Kontemporer (Malang: UIN-Malang Press: Malang, 2009).

Undang-undang Sistem Pendidikan Nasional (Bandung: Citra Umbara, 2010). 